\title{
Article \\ Naïve Human Macrophages Are Refractory to SARS-CoV-2 Infection and Exhibit a Modest Inflammatory Response Early in Infection
}

\author{
Ziyun Zhang ${ }^{1}\left(\mathbb{D}\right.$, Rebecca Penn $^{1}$, Wendy S. Barclay ${ }^{1}$ and Efstathios S. Giotis ${ }^{1,2, *(D)}$ \\ 1 Department of Infectious Diseases, Imperial College London, London W2 1PG, UK; \\ ziyun.zhang-2@postgrad.manchester.ac.uk (Z.Z.); r.penn18@imperial.ac.uk (R.P.); \\ w.barclay@imperial.ac.uk (W.S.B.) \\ 2 School of Life Sciences, University of Essex, Colchester CO4 3SQ, UK \\ * Correspondence: e.giotis@imperial.ac.uk
}

Citation: Zhang, Z.; Penn, R.; Barclay, W.S.; Giotis, E.S. Naïve Human Macrophages Are Refractory to SARS-CoV-2 Infection and Exhibit a

Modest Inflammatory Response Early in Infection. Viruses 2022, 14, 441. https://doi.org/10.3390/v14020441

Academic Editors: Alessandro Sinigaglia and Luisa Barzon

Received: 3 February 2022

Accepted: 18 February 2022

Published: 21 February 2022

Publisher's Note: MDPI stays neutral with regard to jurisdictional claims in published maps and institutional affiliations.

Copyright: (C) 2022 by the authors. Licensee MDPI, Basel, Switzerland. This article is an open access article distributed under the terms and conditions of the Creative Commons Attribution (CC BY) license (https:// creativecommons.org/licenses/by/ $4.0 /)$.

\begin{abstract}
Involvement of macrophages in the SARS-CoV-2-associated cytokine storm, the excessive secretion of inflammatory/anti-viral factors leading to the acute respiratory distress syndrome (ARDS) in COVID-19 patients, is unclear. In this study, we sought to characterize the interplay between the virus and primary human monocyte-derived macrophages (MDM). MDM were stimulated with recombinant IFN- $\alpha$ and/or infected with either live or UV-inactivated SARS-CoV-2 or with two reassortant influenza viruses containing external genes from the H1N1 PR8 strain and heterologous internal genes from a highly pathogenic avian $\mathrm{H} 5 \mathrm{~N} 1$ or a low pathogenic human seasonal H1N1 strain. Virus replication was monitored by qRT-PCR for the $E$ viral gene for SARS-CoV-2 or $M$ gene for influenza and $\mathrm{TCID}_{50}$ or plaque assay, and cytokine levels were assessed semiquantitatively with qRT-PCR and a proteome cytokine array. We report that MDM are not susceptible to SARSCoV-2 whereas both influenza viruses replicated in MDM, albeit abortively. We observed a modest cytokine response in SARS-CoV-2 exposed MDM with notable absence of IFN- $\beta$ induction, which was instead strongly induced by the influenza viruses. Pre-treatment of MDM with IFN- $\alpha$ enhanced proinflammatory cytokine expression upon exposure to virus. Together, the findings concur that the hyperinflammation observed in SARS-CoV-2 infection is not driven by macrophages.
\end{abstract}

Keywords: macrophages; SARS-CoV-2; influenza; infectivity; cytokines

\section{Introduction}

The ongoing COVID-19 pandemic has generated many urgent questions on the diverse clinical manifestations of the causative agent severe acute respiratory syndrome coronavirus 2 (SARS-CoV-2). SARS-CoV-2 requires the binding of its spike surface protein to a cellular receptor, the angiotensin-converting enzyme 2 (ACE2), to gain entry into host cells and activation by a host cell proteases TMPRSS2 [1-3]. The variable expression of ACE2 in different tissues across individuals and polymorphisms in both ACE2 and TMPRSS2 genes contribute to COVID-19 severity/fatality variations [4-7]. However, the severity of the disease outcome is widely believed to be associated with a derangement of the immune system such as a delayed type I/III interferon response and underlying co-morbidities in infected patients [8,9]. One of the perplexing hallmarks of SARS-CoV-2 infection is the exacerbated inflammatory response in severe COVID-19 patients resulting in excessive release of pro-inflammatory cytokines known as "cytokine storm", leading in turn to detrimental alveolar damage and fibrosis, progressive respiratory failure and multiple organ dysfunction [10]. A similar excessive inflammatory reaction has been observed in other zoonotic respiratory viruses such as SARS and MERS coronaviruses as well as human infections with avian influenza viruses such as H5N1 [11-13] whereas seasonal influenza induces a less severe response [14]. The prototypical influenza virus-induced cytokine 
storm has been described to originate from several cell types such as tissue macrophages, mast, endothelial, and epithelial cells [15]. These cells upon virus stimulation release initially TNF- $\alpha$ and IL-1B, which in turn stimulate the release of other cytokines mainly IL-1, IL-6, IL-8 and macrophage inflammatory protein- $1 \alpha$ (MIP- $1 \alpha)[13,15,16]$. Although both influenza and COVID-19 are associated with hyperinflammation, there are marked differences between the two conditions in respect of origin, biochemical abnormalities and pathophysiology [17]. Nonetheless, numerous studies have positively correlated the elevated plasma levels of key proinflammatory cytokines in patients with disease severity and mortality for both COVID-19 and highly pathogenic influenza [13-15,18,19].

Understanding the precise drivers of SARS-CoV-2-induced hyperinflammation and their correlation to disease outcome is crucial to guide targeted therapeutic interventions. The degree to which SARS-CoV-2 targets the diverse cytokine-producing cells (i.e., macrophages, $\mathrm{B}$ and $\mathrm{T}$ lymphocytes, mast cells, endothelial cells, fibroblasts and various stromal cells) has not yet been fully elucidated; hence, their individual role in initiating, contributing, and/or sustaining the cytokine storm remains unclear. A transcriptomic study reported that SARS-CoV-2 sequencing reads were detected in COVID-19 patients' peripheral blood mononuclear cells [20], suggesting that SARS-CoV-2 may be able to replicate in specific immune cell subsets. Infection of these cell subsets may explain the persistence of the virus after pneumonia is resolved in some COVID-19 patients [21]. Macrophages, in particular, are critical for activation and resolution of systemic inflammation and are rapid producers of both proinflammatory and regulatory cytokines in response to local inflammation and pathogen infection [22]. Post-mortem analyses and sequencing approaches have revealed that the lungs of COVID-19 patients with severe disease are infiltrated with macrophages suggesting they play a key role in COVID-19 pathophysiology [23-25]. Earlier reports suggested that alveolar macrophages are infected by SARS-CoV-2 [24-26] and that the diverse expression of ACE2 on macrophages among individuals might govern the severity of SARS-CoV-2 infection [27]. Since then, several studies have demonstrated that macrophages are not permissive to SARS-CoV-2 infection [28-31]. Conversely, some reports argue that macrophages orchestrate the cytokine storm $[21,24,25,30,32]$ while others propose that macrophages play a secondary role in the virus-associated inflammation [29,31].

Here, we report that primary macrophages are refractory to SARS-CoV-2 and induce modest levels of pro-inflammatory cytokines upon SARS-CoV-2 infection compared to two influenza strains. Pre-exposure of macrophages to exogenous IFN- $\alpha$ exacerbated the virus-induced inflammatory response. These results concur with the findings of previous reports that macrophages are not the original source of pro-inflammatory cytokines early during infection.

\section{Materials and Methods}

\subsection{Cells and Viruses}

Human macrophages were purchased from Lonza Group AG (Basel, Switzerland) and were generated in the presence of human macrophage colony-stimulating factor (hM-CSF) from $\mathrm{CD} 14^{+}$human monocytes. The monocytes derived from a 54-year-old, HBV-, HCVand HIV-negative, African American male. The macrophages were seeded $5 \times 10^{5}(0.5 \mathrm{~mL})$ per well, in 24-well plates, with X-Vivo 15 media (Lonza Group AG), $25 \mathrm{ng} / \mu \mathrm{L}$ of hM-CSF (Gibco, New York, NY, USA), and 10\% foetal bovine serum (Gibco, Glasgow, UK). African green monkey kidney cells (Vero E6; ATCC CRL-1586) were maintained in DMEM, 10\% FCS, $1 \%$ non-essential amino acids (NEAA) and $1 \%$ penicillin/streptomycin (P/S). Human epithelial colorectal adenocarcinoma cells (Caco-2; ATCC HTB-37) and human lung cancer cells (Calu-3; ATCC HTB-55) were maintained in DMEM, 20\% FCS, 1\% NEAA and 1\% P/S. All cell cultures in this study were maintained at $37^{\circ} \mathrm{C}$ and $5 \% \mathrm{CO}_{2}$.

The viral strain used in this study was the lineage B.1 SARS-CoV-2/England/IC19/2020 (IC19) isolate (EPI_ISL_475572) [33]. All work involving the use of SARS-CoV-2 was performed in a Biosafety Level 3 (BSL-3) laboratory at St Mary's Campus of Imperial 
College London. For these studies, a SARS-CoV-2 inactivated virus was generated with ultraviolet radiation $(260-285 \mathrm{~nm}$ ) for $2 \mathrm{~min}$. Loss of infectivity was confirmed by the $\mathrm{TCID}_{50}$ test assay in Vero E6 cells. The influenza viruses (6:2 Tky/05 and 6:2 Eng/09) used in this work were rescued by reverse genetics as previously described [34]. The 6 internal genes of 6:2 Tky/05 and 6:2 Eng/09 were from avian highly pathogenic H5N1 influenza A/turkey/Turkey/1//2005 virus (Tky/05), and low pathogenic seasonal 6:2 Eng195 H1N1pdm09 (Eng/09), respectively, combined with haemagglutinin (HA) and neuraminidase (NA) genes from A/Puerto Rico/8/34 (PR8). Briefly, plasmids, encoding internal virus segments from indicated viruses and PR8 HA and NA, were co-transfected into 293-T cells alongside pCAGGs vectors expressing the polymerase and NP proteins were then co-cultured with MDCK cells. Virus stocks were grown on MDCK cells using serum free DMEM supplemented with $1 \mu \mathrm{g} / \mathrm{mL}$ of TPCK trypsin. Viruses were stored in $-80^{\circ} \mathrm{C}$ and titrated on MDCK cells by plaque assay.

\subsection{Treatments}

The viruses were diluted in serum-free DMEM (supplemented with 1\% NEAA and $\mathrm{P} / \mathrm{S}$ ) to a multiplicity of infection of 0.01 or 1 . The inoculum was added to macrophages, Calu-3, Caco-2, or Vero E3 cells and incubated at $37^{\circ} \mathrm{C}$ for $1 \mathrm{~h}$. The inoculum was then removed and cells maintained as described above. Six, 24 or $72 \mathrm{~h}$ post infection (hpi), the culture supernatants were collected and quantified by $\mathrm{TCID}_{50}$ assay on Vero E6 cells by the Spearman-Karber method [35] or qPCR for the SARS-CoV-2 Envelope gene (E). For the IFN- $\alpha$ experiment, macrophages were pre-treated with $1000 \mathrm{U} / \mathrm{mL}$ IFN- $\alpha$ (Invivogen, Nottingham, UK) for $24 \mathrm{~h}$ before SARS-CoV-2 infection. For treatment with lipopolysaccharide (LPS), cells were treated with $10 \mu \mathrm{g} / \mathrm{mL}$ LPS (Invivogen) for $6 \mathrm{~h}$.

\subsection{Real-Time Quantitative Reverse Transcription PCR ( $q P C R)$}

For SARS-CoV-2 envelope $(E)$ and influenza matrix $(M)$ gene qPCR, RNA was extracted from virus supernatants using the QIAmp Viral RNA kit (Qiagen, Crawley, UK) as described by the manufacturer (Qiagen, UK). qPCR was performed using the AgPath RT-PCR (Life Technologies, Paisley, UK) kit on a QuantStudio 7 Flex Real-Time PCR system (Applied Biosystems) with the following primers for the $E$ gene: forward: $5^{\prime}-$ ACAGGTACGTTAATAGTTAATAGCGT-3' ${ }^{\prime}$, reverse: $5^{\prime}$-ATATTGCAGCAGTACGCACACA$3^{\prime}$, probe:FAM-ACACTAGCCATCCTTACTGCGCTTCG-BBQ. For $M$ vRNA and mRNA analysis, primers and procedures were described previously [34]. A standard curve was also generated using viral RNA dilutions of known copy number to allow absolute quantification of $E$ and $M$ gene copies from Ct values.

Cell RNA isolation and RT-qPCR was performed using procedures described previously [36] using the 7900HT Fast Real-Time PCR System (Applied Biosystems, Foster City, CA, USA). Primers for GAPDH, TNF- $\alpha$, IP-10, IL-6, IL-8, HLA-DR, IFN- $\alpha$, IFN- $\beta$, and ACE2 have been described elsewhere [37-39]. The output $C t$ values and dissociation curves were analysed using SDS v2.3 and RQ Manager v1.2 (Applied Biosystems). Gene expression data were normalized against the housekeeping gene GAPDH and compared with the mock controls using the comparative $C_{T}$ method (also referred to as the $2^{-\Delta \Delta C T}$ method [40]. All samples were loaded in triplicate.

\subsection{Chemokine and Cytokine Detection}

To assess the expression of cytokines in SARS-CoV-2-infected, uninfected and LPSstimulated macrophages, we used a Proteome Profiler ${ }^{\mathrm{TM}}$ Human XL Cytokine Array Kit (R\&D Systems, Minneapolis, MN, USA) which contained 102 different capture antibodies that were spotted on a nitrocellulose membrane, according to the manufacturer's protocol. Immunospots were imaged with the Azure c600 Gel Imaging System (Azure Biosystems, Dublin, CA, USA) and data (Figure S1) were analysed as spot intensities using Image J (Laboratory for Optical and Computational Instrumentation, WI, USA). For each protein, 
the average signal of duplicate spots was calculated, corrected for background signals, and normalized to the average signal of the membrane reference spots (relative pixel intensity).

\subsection{Statistical Analyses}

To determine the significance of differences between experimental groups, one-way ANOVA analysis followed by Tukey's multiple comparisons test were carried out. $p$-values were set at $0.05(p \leq 0.05)$ unless indicated otherwise. Error bars represent standard deviation (SD). All data analyses and preparation of graphs were carried out with GraphPad Prism version 8.01 (GraphPad Software, San Diego, CA, USA).

\section{Results and Discussions}

\subsection{Macrophages Are Refractory to SARS-CoV-2 Infection}

Severe infections of SARS-CoV-2 are associated with a cytokine storm characterised by high levels of IL-6 and TNF- $\alpha$ in patients [41]. The original source of this hyperinflammation has not yet been elucidated. Macrophages play a critical role in immune defence against virus infections and are critical for activation and resolution of systemic inflammation [42-44]. The degree to which macrophages contribute to SARS-CoV-2 propagation within the host and host immune responses to the infection is not yet clear.

We initially investigated the ability of human macrophages to support SARS-CoV-2 replication. We infected monolayers of primary human monocyte-derived macrophages (MDM) with a SARS-CoV-2 B.1 lineage strain and two recombinant influenza isolates (6:2 Tky/05 and 6:2 Eng/09) at a multiplicity of infection (MOI) of 0.01 or 1 . The engineered viruses have an identical ability to bind and enter cells because they encode the same HA/NA pairing (PR8), but differ in their interaction with factors inside the infected cells depending on the human (H1N1 6:2 Eng/09) or avian (H5N1 6:2 Tky/05) virus origin of the segments encoding the internal genes and induce distinct innate immune responses [34].

We assessed productive replication of SARS-CoV-2 by titrating infectious virus in the cell supernatant at 24 and $72 \mathrm{~h}$ post-infection (hpi) with a standard TCID ${ }_{50}$ assay on Vero E6 cells, and compared virus yields with those from Calu-3, Vero E6 and Caco-2. We also extracted RNA from the supernatants and the infected cells at $6 \mathrm{hpi}$ and conducted qRT-PCR for the viral transcripts ( $E$ for SARS-CoV-2 and $M$ for influenza viruses). We observed no cytopathic effect, no $E$ gene RT-PCR signal (data not shown) and no infectious yield (Figure 1A) in the cell lysate or the cell-free supernatant of macrophages, respectively, during infection with SARS-CoV-2. In contrast Caco-2, Vero E6 and Calu-3 cell lines produced high viral loads $\left(4 \times 10^{5}-5.5 \times 10^{5} \mathrm{TCID}_{50} / \mathrm{mL}\right)$ (Figure 1A). Together these findings indicate that macrophages do not support SARS-CoV-2 replication in line with other reports [28-31]. In contrast, the influenza $M$ gene was detected in cell lysates at $6 \mathrm{hpi}$, more so in 6:2 Eng/09 infected macrophages (Figure S2). However, no significant increase in the $M$ gene was detected in the cell culture supernatant infected by either influenza virus at 24 or $72 \mathrm{hpi}$ and no infectious virus was measured by a plaque assay. Thus, the replication of these viruses in MDM is abortive, consistent with a report that only a small subset of influenza strains can productively replicate in primary human macrophages [45]. 
A

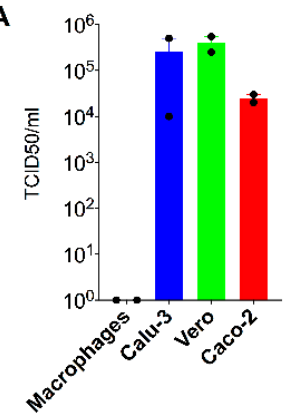

D

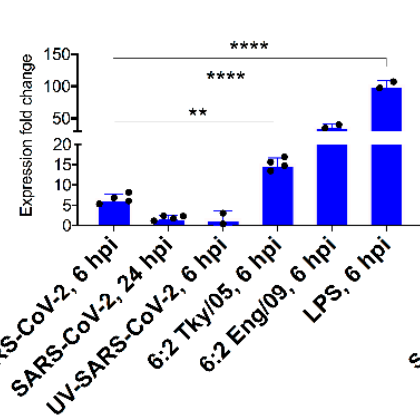

B

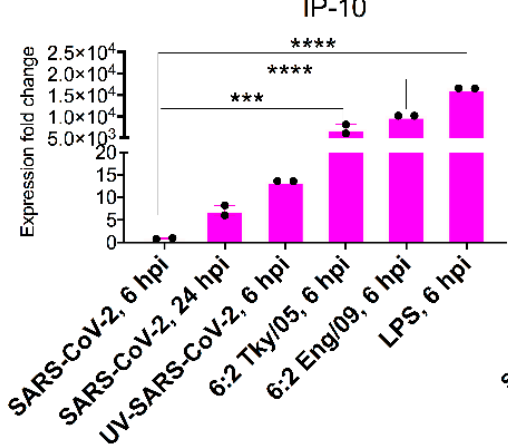

E
IL-6

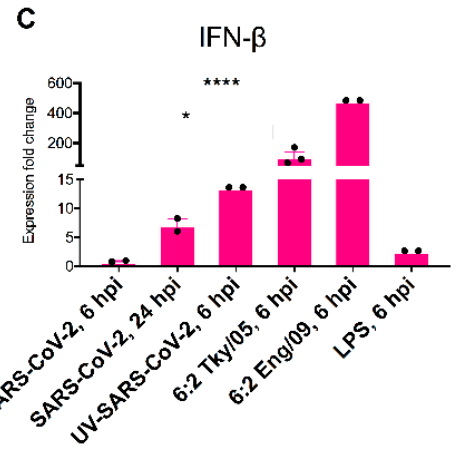

F
IL-8
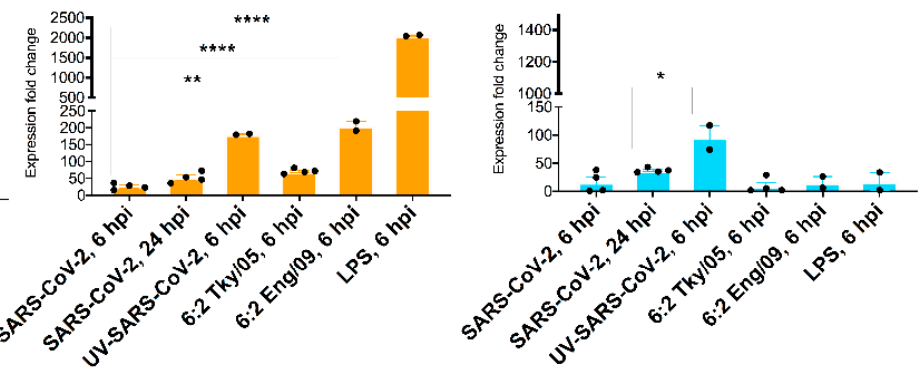

G

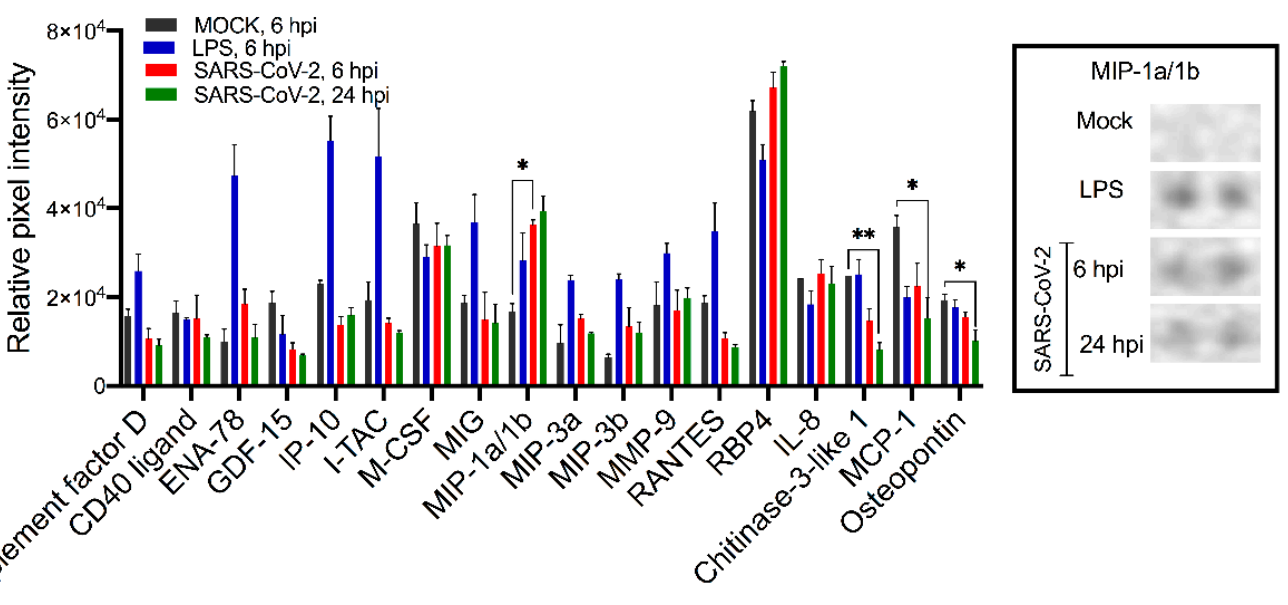

Figure 1. Primary macrophages are refractory to SARS-CoV-2 infection and demonstrate moderate induction of proinflammatory cytokines upon exposure. (A) SARS-CoV-2 titres in MDM, Calu3, Vero E6 and Caco-2 at 72 hpi (MOI: 0.01) as determined by TCID50 assay. (B-F) The bar graphs depict the relative gene expression fold change of (B) IP-10, (C) IFN- $\beta$, (D) TNF- $\alpha$, (E) IL-6 and (F) IL-8 mRNAs in MDM exposed to SARS-CoV-2 (MOI: 1), influenza strains: 6:2 Tky/05 or 6:2 Eng/09 and MDM stimulated with LPS $(10 \mu \mathrm{g} / \mu \mathrm{L})$ compared with non-exposed/untreated control. Total RNA was isolated from cells at 6 and $24 \mathrm{hpi}$. The genes were quantified by qRT-PCR. Results are presented relative to the control non-exposed/untreated cell levels $\left(2^{-\Delta \Delta C T}\right)$. (G) (Left) The differential expression shown as mean relative pixel density and SD of 18 cytokines associated with COVID-19 screened out by the Proteome Profiler Human XL Cytokine Array kit (spotted with 102 different cytokine antibodies). The cytokine array was performed according to the manufacturer instructions using supernatant from mock, LPS-stimulated and SARS-CoV-2 exposed MDM at 6 and $24 \mathrm{hpi}$ (samples derived from the same assays with Figure 1B-F). (Right) Dots corresponding to MIP- $1 \alpha /-1 \beta$. Statistical analysis was performed by using a one-way analysis of variance (ANOVA) followed by Tukey's test. ${ }^{* * * *}, p<0.00011^{* * *}, p<0.0011^{* *}, p<0.01^{*}, p<0.05$. Data derived from at least two independent experiments (shown as dots); means and SD are shown. 


\subsection{Macrophages Exhibit Modest Pro-Inflammatory Responses during SARS-CoV-2 Infection}

Having established that MDM did not support productive replication of either SARSCoV-2 or influenza, we then examined the extent to which exposure of MDM to SARSCoV-2 and influenza viruses can lead to activation and production of pro-inflammatory cytokines early in infection (6 hpi). We assessed the mRNA induction of innate antiviral and proinflammatory cytokines TNF- $\alpha$, IP-10, IFN- $\alpha$, IFN- $\beta$, IL-6, and IL-8 in exposed or lipopolysaccharide (LPS)-activated MDM. Cell response following exposure to UVinactivated, replication-deficient SARS-CoV-2 virus was also assessed. Results are shown as expression fold change against mock MDM (Figure 1B-F). The results demonstrate that SARS-CoV-2 exposure induced significantly lower expression of IP-10, TNF- $\alpha$, IL-6 mRNA compared to exposure to influenza viruses or stimulation with LPS at 6 hpi. Numerically higher but still modest levels of these cytokines were detected in SARS-CoV-2 infected MDM at 24 hpi. The UV-inactivated virus retained the ability to induce IL- 6 and IL-8 production (180- and 95-fold, respectively). The 6:2 Eng/09 strain induced significantly more (2.5-fold) the expression of TNF- $\alpha$ compared to 6:2 Tky/05. Expression of IFN- $\alpha$ was below detectable levels in all conditions tested (data not shown).

Next, we determined semiquantitatively the cytokine protein levels in the supernatants of mock (6 hpi), SARS-CoV-2-exposed (6 and $24 \mathrm{hpi}$ ) and LPS-stimulated (hpi) MDM with a Proteome Profiler Human XL Cytokine Array. The array contains four membranes, each spotted in duplicate with 102 different cytokine antibodies. A densitometric evaluation revealed that the proinflammatory cytokines TNF- $\alpha$, IP-10, IFN- $\gamma$, IL- 6 and IL-8 cytokines were minimally detected in SARS-CoV-2-exposed MDM compared to mock MDM in line with the qRT-PCR results (Figure 1G). Instead, we noticed a significant induction of the macrophage inflammatory protein (MIP-) $1 \alpha$ and $1 \beta$. MIP- $1 \alpha /-1 \beta$ are monocyte cytokines with inflammatory and chemotactic properties, which interact with CCR1, CCR4, and CCR5 [46] and have been found to be elevated in blood levels of COVID-19 patients (notably those admitted to intensive care units) [47]. Interestingly, the expression of three other cytokines was significantly reduced by SARS-CoV-2 (Figure 1G): monocyte chemoattractant protein 1 (MCP1), osteopontin (OPN), and chitinase 3-like 1 (CHI3L1). MCP-1 is a chemokine that attracts monocytes and basophils, but not neutrophils or eosinophils [48]. OPN is an integrin-binding glyco-phosphoprotein involved in the modulation of leukocyte activation [49] and CHI3L1 is a critical regulator of inflammation and innate immunity and a stimulator of ACE2 [50]. The levels of these cytokines are elevated in blood levels of COVID-19 patients and are associated with increased severity of disease. Our findings suggest that secretion of these cytokines is not associated with macrophages at least early in infection.

\subsection{Priming Macrophages with IFN $\alpha$ Boosts Transcription of Proinflammatory Cytokines but Does Not Allow Productive Replication}

During virus infections, the majority of immune and epithelial cells produce type I interferons (IFNs: IFN- $\alpha,-\beta$ and $-\omega$ ) upon sensing a virus. The IFNs do not directly kill the virus. They orchestrate a coordinated antiviral program via the Janus kinase (JAK)signal transducers, the activators of the transcription (STAT) signalling pathway and the expression of interferon-stimulated genes (ISGs), whose protein products directly inhibit virus infection [51]. SARS-CoV-2 has been reported to antagonise type I IFN responses in primary cells [52] and severe COVID-19 patients display impaired IFN- $\alpha$ production [53]. We explored whether pre-treatment of MDM with IFN- $\alpha$ can trigger an inflammatory response. MDM were pre-treated overnight with exogenous recombinant IFN- $\alpha$ and exposed to SARS-CoV-2 for $24 \mathrm{~h}$ as previously. Results show significantly higher expression levels of TNF- $\alpha$, IL-6, IL-8 and the macrophage activation marker HLA-DR in IFN- $\alpha$ treated cells compared to the untreated ones (Figure 2A-D) while levels of IFN- $\beta$ (Figure 2E) and IP-10 (not presented) were below the detection limit. 

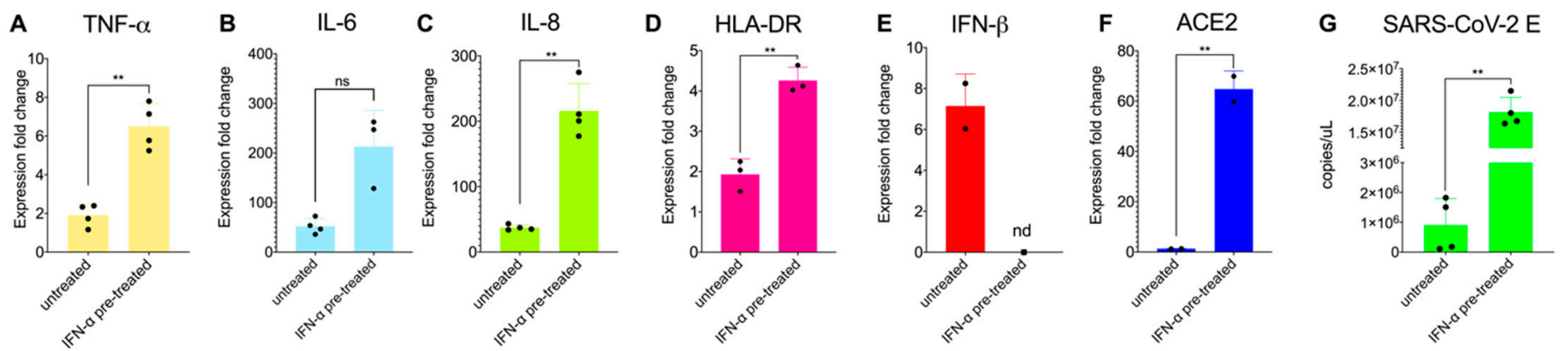

Figure 2. Proinflammatory response is enhanced by pretreatment with IFN- $\alpha$ in primary macrophages exposed to SARS-CoV-2 (A-E). Relative fold induction of gene expression ((A) TNF- $\alpha,(\mathbf{B})$ IL-6, (C) IL8, (D) HLA-DR and (E) IFN- $\beta$ and (F) ACE2) in MDM in response to overnight pre-treatment with IFN- $\alpha$ (1000 IU/mL) and infection with SARS-CoV-2 for $24 \mathrm{~h}$ (MOI:1). (G) Quantification of subgenomic E RNA (qRT-PCR) in MDM exposed to SARS-CoV-2 and/or pre-treated with IFN- $\alpha$. Results are presented relative to the control cell levels $\left(2^{-\Delta \Delta C T}\right)$. Statistical analysis was performed by using a paired $t$-test. ${ }^{* *} p<0.01$. Data derived from at least two independent experiments (shown as dots); means and SD are shown.

This finding suggests that exogenous stimuli such as secreted interferons from infected epithelial or immune cells, i.e., dendritic cells, may paradoxically exacerbate the inflammatory response of macrophages in line with other reports on SARS-CoV and SARSCoV-2 $[54,55]$. We suspect that the cells we worked with here may reflect a more dominant M2 macrophage population and the observed phenotypes may differ in tissue-resident macrophages. In this study, we examined gene expression during the critical early time points ( 6 and $24 \mathrm{hpi}$ ) following exposure of MDM to the virus. It is possible that a more extended exposure (72 hpi or more) might result in more significant cytokine responses. Arguably, ex vivo cultures of primary macrophages, albeit valuable, have a limited lifespan which can affect cell polarization and transcriptional responses after extended periods of culture. Nevertheless, our findings are aligned with reports that macrophages are unlikely to drive the initial wave of pro-inflammatory cytokines upon SARS-CoV-2 infection [29,31]. In addition, the substantial increase in induction of proinflammatory cytokines upon IFNstimulation suggests that macrophages may participate in secondary or ensuing waves of inflammatory responses leading to ARDS in severe COVID-19 patients.

Interestingly, we found a significant increase of the subgenomic $E$ gene in the cell lysate of IFN-treated MDM but infection was still abortive as we found no new infectious particles in the supernatant (by TCID 50 assay and qPCR for the $E$ gene; Figure 2G). Like others [56], we found that pre-treatment of MDM with IFN- $\alpha$ resulted in the induction of ACE2 mRNA (Figure 2F). ACE2 is the receptor that SARS-CoV-2 uses to infect epithelial cells of lung alveoli and also an ISG [57]. However, a previous report that the ACE2 isoform upregulated by interferon is non-functional for SARS-CoV-2 entry [57], so our results might be explained by other changes to the cells that render them more infectable by the virus.

\section{Conclusions}

Conflicting reports surround the role of macrophages in SARS-CoV-2 immunopathogenesis and in particular in triggering the cytokine storm that mediates the severity of ARDS in COVID-19 patients' lungs. This study provides further evidence that macrophages are refractory to SARS-CoV-2. We report that SARS-CoV-2 failed to trigger excessive production of cytokines in macrophages at the transcription and protein level, compared to two influenza viruses. We found no evidence for pro-inflammatory cytokine responses upon SARS-CoV-2 exposure. We argue that limited viral internalization or a low replication of SARS-CoV-2 in macrophages may explain the low levels of cytokines induced upon exposure compared with influenza viruses. Mirroring other reports, we demonstrate that pre-treatment of macrophages with IFN- $\alpha$ promoted the induction of several pro-inflammatory cytokines but did not render them vulnerable to the virus despite the 
increased transcription of ACE2. In conclusion, macrophages are unlikely to drive the early wave of pro-inflammatory factors observed in COVID-19 patients with severe disease, but they may exacerbate immune responses later in infection.

Supplementary Materials: The following supporting information can be downloaded at: https: / / www.mdpi.com/article/10.3390/v14020441/s1, Figure S1: Differential cytokine/chemokine production levels modulated by SARS-CoV-2 in MDM. Human XL Cytokine array of secreted factors in the cell supernatant of (A) mock-infected, (B) 24 h post LPS stimulation, (C) 6 hpi (MOI:1) and (D) 24 hpi (MOI:1) MDM. Figure S2: Replication of 6:2 Eng/09 and 6:2 Tky/05 influenza strains in MDM is abortive. Quantification of $M$ gene expression levels in cell lysates (red) and supernatants (blue) of MDM infected with recombinant 6:2 Eng/09 (A) or 6:2 Tky/05 (B) influenza strains (MOI:1) at 6 and 24 hpi by qRT-PCR. Bars represent Mean \pm SD.

Author Contributions: Z.Z. performed experiments, analysed data and wrote first draft of the manuscript; R.P. and E.S.G. performed experiments, analysed data and edited the manuscript; W.S.B. and E.S.G. conceptualized the study, supervised activities and edited the manuscript. All authors have read and agreed to the published version of the manuscript.

Funding: Research was supported by a Wellcome Trust New Investigator award (104771/Z/14/Z) to Marcus Dorner.

Data Availability Statement: The data used and/or analysed during the current study are available, only for sections non-infringing personal information, from the corresponding author on reasonable request.

Acknowledgments: We thank Jonathan Brown, Jie Zhou, and Thomas Peacock for their technical advice and assistance.

Conflicts of Interest: The authors declare no conflict of interest.

\section{References}

1. Chen, Y.; Guo, Y.; Pan, Y.; Zhao, Z.J. Structure analysis of the receptor binding of 2019-nCoV. Biochem. Biophys Res. Commun. 2020, 525, 135-140. [CrossRef] [PubMed]

2. Hoffmann, M.; Kleine-Weber, H.; Schroeder, S.; Kruger, N.; Herrler, T.; Erichsen, S.; Schiergens, T.S.; Herrler, G.; Wu, N.H.; Nitsche, A.; et al. SARS-CoV-2 Cell Entry Depends on ACE2 and TMPRSS2 and Is Blocked by a Clinically Proven Protease Inhibitor. Cell 2020, 181, 271-280. [CrossRef] [PubMed]

3. Tay, M.Z.; Poh, C.M.; Renia, L.; MacAry, P.A.; Ng, L.F.P. The trinity of COVID-19: Immunity, inflammation and intervention. Nat. Rev. Immunol. 2020, 20, 363-374. [CrossRef] [PubMed]

4. Hikmet, F.; Mear, L.; Edvinsson, A.; Micke, P.; Uhlen, M.; Lindskog, C. The protein expression profile of ACE2 in human tissues. Mol. Syst. Biol. 2020, 16, e9610. [CrossRef] [PubMed]

5. Chen, J.; Jiang, Q.; Xia, X.; Liu, K.; Yu, Z.; Tao, W.; Gong, W.; Han, J.J. Individual variation of the SARS-CoV-2 receptor ACE2 gene expression and regulation. Aging Cell 2020, 19, e13168. [CrossRef] [PubMed]

6. Zhao, Y.; Zhao, Z.; Wang, Y.; Zhou, Y.; Ma, Y.; Zuo, W. Single-Cell RNA Expression Profiling of ACE2, the Receptor of SARS-CoV-2. Am. J. Respir. Crit. Care Med. 2020, 202, 756-759. [CrossRef]

7. David, A.; Parkinson, N.; Peacock, T.P.; Pairo-Castineira, E.; Khanna, T.; Cobat, A.; Tenesa, A.; Sancho-Shimizu, V.; Casanova, J.L.; Abel, L.; et al. A common TMPRSS2 variant has a protective effect against severe COVID-19. Curr. Res. Transl. Med. 2022, 70, 103333. [CrossRef]

8. Brodin, P. Immune determinants of COVID-19 disease presentation and severity. Nat. Med. 2021, 27, 28-33. [CrossRef]

9. Galani, I.E.; Rovina, N.; Lampropoulou, V.; Triantafyllia, V.; Manioudaki, M.; Pavlos, E.; Koukaki, E.; Fragkou, P.C.; Panou, V.; Rapti, V.; et al. Untuned antiviral immunity in COVID-19 revealed by temporal type I/III interferon patterns and flu comparison. Nat. Immunol. 2021, 22, 32-40. [CrossRef]

10. Huang, Q.; Wu, X.; Zheng, X.; Luo, S.; Xu, S.; Weng, J. Targeting inflammation and cytokine storm in COVID-19. Pharmacol. Res. 2020, 159, 105051. [CrossRef] [PubMed]

11. Zhang, Y.Y.; Li, B.R.; Ning, B.T. The Comparative Immunological Characteristics of SARS-CoV, MERS-CoV, and SARS-CoV-2 Coronavirus Infections. Front. Immunol. 2020, 11, 2033. [CrossRef]

12. Peiris, J.S.; Hui, K.P.; Yen, H.L. Host response to influenza virus: Protection versus immunopathology. Curr. Opin. Immunol. 2010, 22, 475-481. [CrossRef] [PubMed]

13. Ryabkova, V.A.; Churilov, L.P.; Shoenfeld, Y. Influenza infection, SARS, MERS and COVID-19: Cytokine storm-The common denominator and the lessons to be learned. Clin. Immunol. 2021, 223, 108652. [CrossRef] [PubMed] 
14. Liu, Q.; Zhou, Y.H.; Yang, Z.Q. The cytokine storm of severe influenza and development of immunomodulatory therapy. Cell. Mol. Immunol. 2016, 13, 3-10. [CrossRef]

15. Guo, X.J.; Thomas, P.G. New fronts emerge in the influenza cytokine storm. Semin. Immunopathol. 2017, 39, 541-550. [CrossRef]

16. Jaffer, U.; Wade, R.G.; Gourlay, T. Cytokines in the systemic inflammatory response syndrome: A review. HSR Proc. Intensive Care Cardiovasc. Anesth. 2010, 2, 161-175. [PubMed]

17. Morris, G.; Bortolasci, C.C.; Puri, B.K.; Marx, W.; O’Neil, A.; Athan, E.; Walder, K.; Berk, M.; Olive, L.; Carvalho, A.F.; et al. The cytokine storms of COVID-19, H1N1 influenza, CRS and MAS compared. Can one sized treatment fit all? Cytokine 2021, 144, 155593. [CrossRef]

18. Del Valle, D.M.; Kim-Schulze, S.; Huang, H.H.; Beckmann, N.D.; Nirenberg, S.; Wang, B.; Lavin, Y.; Swartz, T.H.; Madduri, D.; Stock, A.; et al. An inflammatory cytokine signature predicts COVID-19 severity and survival. Nat. Med. 2020, 26, 1636-1643. [CrossRef]

19. Jamilloux, Y.; Henry, T.; Belot, A.; Viel, S.; Fauter, M.; El Jammal, T.; Walzer, T.; Francois, B.; Seve, P. Should we stimulate or suppress immune responses in COVID-19? Cytokine and anti-cytokine interventions. Autoimmun. Rev. 2020, 19, 102567. [CrossRef]

20. Xiong, Y.; Liu, Y.; Cao, L.; Wang, D.; Guo, M.; Jiang, A.; Guo, D.; Hu, W.; Yang, J.; Tang, Z.; et al. Transcriptomic characteristics of bronchoalveolar lavage fluid and peripheral blood mononuclear cells in COVID-19 patients. Emerg. Microbes Infect. 2020, 9 , 761-770. [CrossRef]

21. Tang, Y.; Liu, J.; Zhang, D.; Xu, Z.; Ji, J.; Wen, C. Cytokine Storm in COVID-19: The Current Evidence and Treatment Strategies. Front. Immunol. 2020, 11, 1708. [CrossRef] [PubMed]

22. Hamidzadeh, K.; Christensen, S.M.; Dalby, E.; Chandrasekaran, P.; Mosser, D.M. Macrophages and the Recovery from Acute and Chronic Inflammation. Annu. Rev. Physiol. 2017, 79, 567-592. [CrossRef] [PubMed]

23. Bost, P.; Giladi, A.; Liu, Y.; Bendjelal, Y.; Xu, G.; David, E.; Blecher-Gonen, R.; Cohen, M.; Medaglia, C.; Li, H.; et al. Host-Viral Infection Maps Reveal Signatures of Severe COVID-19 Patients. Cell 2020, 181, 1475-1488.e12. [CrossRef]

24. Feng, Z.; Diao, B.; Wang, R.; Wang, G.; Wang, C.; Tan, Y.; Liu, L.; Wang, C.; Liu, Y.; Liu, Y.; et al. The Novel Severe Acute Respiratory Syndrome Coronavirus 2 (SARS-CoV-2) Directly Decimates Human Spleens and Lymph Nodes. medRxiv 2020 [CrossRef]

25. Jafarzadeh, A.; Chauhan, P.; Saha, B.; Jafarzadeh, S.; Nemati, M. Contribution of monocytes and macrophages to the local tissue inflammation and cytokine storm in COVID-19: Lessons from SARS and MERS, and potential therapeutic interventions. Life Sci. 2020, 257, 118102. [CrossRef] [PubMed]

26. Chu, H.; Chan, J.F.; Yuen, T.T.; Shuai, H.; Yuan, S.; Wang, Y.; Hu, B.; Yip, C.C.; Tsang, J.O.; Huang, X.; et al. Comparative tropism, replication kinetics, and cell damage profiling of SARS-CoV-2 and SARS-CoV with implications for clinical manifestations, transmissibility, and laboratory studies of COVID-19: An observational study. Lancet Microbe 2020, 1, e14-e23. [CrossRef]

27. Abassi, Z.; Knaney, Y.; Karram, T.; Heyman, S.N. The Lung Macrophage in SARS-CoV-2 Infection: A Friend or a Foe? Front. Immunol. 2020, 11, 1312. [CrossRef]

28. Banerjee, A.; Nasir, J.A.; Budylowski, P.; Yip, L.; Aftanas, P.; Christie, N.; Ghalami, A.; Baid, K.; Raphenya, A.R.; Hirota, J.A.; et al. Isolation, Sequence, Infectivity, and Replication Kinetics of Severe Acute Respiratory Syndrome Coronavirus 2. Emerg. Infect. Dis. 2020, 26, 2054-2063. [CrossRef]

29. Niles, M.A.; Gogesch, P.; Kronhart, S.; Ortega Iannazzo, S.; Kochs, G.; Waibler, Z.; Anzaghe, M. Macrophages and Dendritic Cells Are Not the Major Source of Pro-Inflammatory Cytokines Upon SARS-CoV-2 Infection. Front. Immunol. 2021, $12,647824$. [CrossRef]

30. Boumaza, A.; Gay, L.; Mezouar, S.; Bestion, E.; Diallo, A.B.; Michel, M.; Desnues, B.; Raoult, D.; La Scola, B.; Halfon, P.; et al. Monocytes and macrophages, targets of SARS-CoV-2: The clue for Covid-19 immunoparalysis. J. Infect. Dis. 2021, 224, 395-406. [CrossRef]

31. Thorne, L.G.; Reuschl, A.K.; Zuliani-Alvarez, L.; Whelan, M.V.X.; Turner, J.; Noursadeghi, M.; Jolly, C.; Towers, G.J. SARS-CoV-2 sensing by RIG-I and MDA5 links epithelial infection to macrophage inflammation. EMBO J. 2021, 40, e107826. [CrossRef] [PubMed]

32. Yang, D.; Chu, H.; Hou, Y.; Chai, Y.; Shuai, H.; Lee, A.C.; Zhang, X.; Wang, Y.; Hu, B.; Huang, X.; et al. Attenuated Interferon and Proinflammatory Response in SARS-CoV-2-Infected Human Dendritic Cells Is Associated With Viral Antagonism of STAT1 Phosphorylation. J. Infect. Dis. 2020, 222, 734-745. [CrossRef]

33. Leach, D.A.; Mohr, A.; Giotis, E.S.; Cil, E.; Isac, A.M.; Yates, L.L.; Barclay, W.S.; Zwacka, R.M.; Bevan, C.L.; Brooke, G.N. The antiandrogen enzalutamide downregulates TMPRSS2 and reduces cellular entry of SARS-CoV-2 in human lung cells. Nat. Commun. 2021, 12, 4068. [CrossRef] [PubMed]

34. Li, H.; Bradley, K.C.; Long, J.S.; Frise, R.; Ashcroft, J.W.; Hartgroves, L.C.; Shelton, H.; Makris, S.; Johansson, C.; Cao, B.; et al. Internal genes of a highly pathogenic H5N1 influenza virus determine high viral replication in myeloid cells and severe outcome of infection in mice. PLoS Pathog. 2018, 14, e1006821. [CrossRef] [PubMed]

35. Kärber, G. Beitrag zur kollektiven Behandlung pharmakologischer Reihenversuche. Naunyn-Schmiedebergs Arch. Exp. Pathol. Pharmakol. 1931, 162, 480-483. [CrossRef]

36. Giotis, E.S.; Ross, C.S.; Robey, R.C.; Nohturfft, A.; Goodbourn, S.; Skinner, M.A. Constitutively elevated levels of SOCS1 suppress innate responses in DF-1 immortalised chicken fibroblast cells. Sci. Rep. 2017, 7, 17485. [CrossRef] [PubMed] 
37. Lau, S.K.P.; Lau, C.C.Y.; Chan, K.H.; Li, C.P.Y.; Chen, H.; Jin, D.Y.; Chan, J.F.W.; Woo, P.C.Y.; Yuen, K.Y. Delayed induction of proinflammatory cytokines and suppression of innate antiviral response by the novel Middle East respiratory syndrome coronavirus: Implications for pathogenesis and treatment. J. Gen. Virol. 2013, 94, 2679-2690. [CrossRef]

38. Giotis, E.S.; Carnell, G.; Young, E.F.; Ghanny, S.; Soteropoulos, P.; Wang, L.F.; Barclay, W.S.; Skinner, M.A.; Temperton, N. Entry of the bat influenza H17N10 virus into mammalian cells is enabled by the MHC class II HLA-DR receptor. Nat. Microbiol. 2019, 4, 2035-2038. [CrossRef]

39. Long, J.S.; Giotis, E.S.; Moncorge, O.; Frise, R.; Mistry, B.; James, J.; Morisson, M.; Iqbal, M.; Vignal, A.; Skinner, M.A.; et al. Species difference in ANP32A underlies influenza A virus polymerase host restriction. Nature 2016, 529, 101-104. [CrossRef]

40. Pfaffl, M.W. A new mathematical model for relative quantification in real-time RT-PCR. Nucleic Acids Res. 2001, 29, e45. [CrossRef] [PubMed]

41. Liu, Y.; Zhang, C.; Huang, F.; Yang, Y.; Wang, F.; Yuan, J.; Zhang, Z.; Qin, Y.; Li, X.; Zhao, D.; et al. Elevated plasma levels of selective cytokines in COVID-19 patients reflect viral load and lung injury. Natl. Sci. Rev. 2020, 7, 1003-1011. [CrossRef]

42. Buckley, C.D.; Gilroy, D.W.; Serhan, C.N.; Stockinger, B.; Tak, P.P. The resolution of inflammation. Nat. Rev. Immunol. 2013, 13, 59-66. [CrossRef] [PubMed]

43. Guilliams, M.; Ginhoux, F.; Jakubzick, C.; Naik, S.H.; Onai, N.; Schraml, B.U.; Segura, E.; Tussiwand, R.; Yona, S. Dendritic cells, monocytes and macrophages: A unified nomenclature based on ontogeny. Nat. Rev. Immunol. 2014, 14, 571-578. [CrossRef]

44. Kvedaraite, E.; Hertwig, L.; Sinha, I.; Ponzetta, A.; Hed Myrberg, I.; Lourda, M.; Dzidic, M.; Akber, M.; Klingstrom, J.; Folkesson, E.; et al. Major alterations in the mononuclear phagocyte landscape associated with COVID-19 severity. Proc. Natl. Acad. Sci. USA 2021, 118, e2018587118. [CrossRef] [PubMed]

45. Marvin, S.A.; Russier, M.; Huerta, C.T.; Russell, C.J.; Schultz-Cherry, S. Influenza Virus Overcomes Cellular Blocks To Productively Replicate, Impacting Macrophage Function. J. Virol. 2017, 91, e01417-16. [CrossRef]

46. Ntanasis-Stathopoulos, I.; Fotiou, D.; Terpos, E. CCL3 Signaling in the Tumor Microenvironment. Adv. Exp. Med. Biol. 2020, 1231, 13-21. [CrossRef] [PubMed]

47. Abers, M.S.; Delmonte, O.M.; Ricotta, E.E.; Fintzi, J.; Fink, D.L.; de Jesus, A.A.A.; Zarember, K.A.; Alehashemi, S.; Oikonomou, V.; Desai, J.V.; et al. An immune-based biomarker signature is associated with mortality in COVID-19 patients. JCI Insight 2021, 6, e144455. [CrossRef]

48. Chen, Y.; Wang, J.; Liu, C.; Su, L.; Zhang, D.; Fan, J.; Yang, Y.; Xiao, M.; Xie, J.; Xu, Y.; et al. IP-10 and MCP-1 as biomarkers associated with disease severity of COVID-19. Mol. Med. 2020, 26, 97. [CrossRef]

49. Hayek, S.S.; Roderburg, C.; Blakely, P.; Launius, C.; Eugen-Olsen, J.; Tacke, F.; Ktena, S.; Keitel, V.; Luedde, M.; Giamarellos-Bourboulis, E.J.; et al. Circulating Osteopontin Levels and Outcomes in Patients Hospitalized for COVID-19. J. Clin. Med. 2021, 10, 3907. [CrossRef]

50. Kamle, S.; Ma, B.; He, C.H.; Akosman, B.; Zhou, Y.; Lee, C.M.; El-Deiry, W.S.; Huntington, K.; Liang, O.; Machan, J.T.; et al Chitinase 3-like-1 is a therapeutic target that mediates the effects of aging in COVID-19. JCI Insight 2021, 6, e148749. [CrossRef]

51. Liu, S.Y.; Sanchez, D.J.; Aliyari, R.; Lu, S.; Cheng, G. Systematic identification of type I and type II interferon-induced antiviral factors. Proc. Natl. Acad. Sci. USA 2012, 109, 4239-4244. [CrossRef] [PubMed]

52. Blanco-Melo, D.; Nilsson-Payant, B.E.; Liu, W.C.; Uhl, S.; Hoagland, D.; Moller, R.; Jordan, T.X.; Oishi, K.; Panis, M.; Sachs, D.; et al Imbalanced Host Response to SARS-CoV-2 Drives Development of COVID-19. Cell 2020, 181, 1036-1045. [CrossRef] [PubMed]

53. Hadjadj, J.; Yatim, N.; Barnabei, L.; Corneau, A.; Boussier, J.; Smith, N.; Pere, H.; Charbit, B.; Bondet, V.; Chenevier-Gobeaux, C.; et al. Impaired type I interferon activity and inflammatory responses in severe COVID-19 patients. Science 2020, 369, 718-724. [CrossRef] [PubMed]

54. Kim, Y.M.; Shin, E.C. Type I and III interferon responses in SARS-CoV-2 infection. Exp. Mol. Med. 2021, 53, 750-760. [CrossRef]

55. Channappanavar, R.; Fehr, A.R.; Vijay, R.; Mack, M.; Zhao, J.; Meyerholz, D.K.; Perlman, S. Dysregulated Type I Interferon and Inflammatory Monocyte-Macrophage Responses Cause Lethal Pneumonia in SARS-CoV-Infected Mice. Cell Host Microbe 2016, 19, 181-193. [CrossRef]

56. Ziegler, C.G.K.; Allon, S.J.; Nyquist, S.K.; Mbano, I.M.; Miao, V.N.; Tzouanas, C.N.; Cao, Y.; Yousif, A.S.; Bals, J.; Hauser, B.M.; et al SARS-CoV-2 Receptor ACE2 Is an Interferon-Stimulated Gene in Human Airway Epithelial Cells and Is Detected in Specific Cell Subsets across Tissues. Cell 2020, 181, 1016-1035.e9. [CrossRef] [PubMed]

57. Ng, K.W.; Attig, J.; Bolland, W.; Young, G.R.; Major, J.; Wrobel, A.G.; Gamblin, S.; Wack, A.; Kassiotis, G. Tissue-specific and interferon-inducible expression of nonfunctional ACE2 through endogenous retroelement co-option. Nat. Genet. 2020, 52, 1294-1302. [CrossRef] 